\title{
Crescimento, qualidade de raízes e atividade da redutase do nitrato em plantas de rabanete submetidas a doses de potássio e fontes de nitrogênio
}

\begin{abstract}
Growth, root quality and nitrate reductase activity in radish plants submitted to potassium doses and
\end{abstract} nitrogen sources

\author{
P. P. S. Soares; N. L. S. Mesquita; J. R. Almeida; R. L. Coutrim; P. A. R. Cairo; \\ L. D. Silva* \\ Programa de Pós-Graduação em Agronomia, Universidade Estadual do Sudoeste da Bahia, 45083-900, Vitória da \\ Conquista-BA, Brasil. \\ *leodias5@yahoo.com.br
}

(Recebido em 16 de abril de 2020; aceito em 12 de junho de 2020)

\begin{abstract}
Nitrogênio e potássio são os nutrientes mais extraídos e exportados pela cultura do rabanete, sendo imprescindíveis para a produtividade e qualidade das raízes produzidas. Desta forma, o presente estudo foi desenvolvido com o objetivo de avaliar alterações no crescimento de plantas e qualidade de raízes de rabanete em função de doses de potássio e fontes de nitrogênio. O experimento foi conduzido em delineamento inteiramente casualizado, com tratamentos arranjados em esquema fatorial 4 x 2 , sendo quatro doses de potássio (K), $0,70,140$ e $210 \mathrm{~kg} \mathrm{ha}^{-1}$ de $\mathrm{K}_{2} \mathrm{O}$ e duas fontes de nitrogênio (N), sulfato de amônio e nitrato de cálcio, com quatro repetições. As plantas foram avaliadas quanto ao crescimento, rendimento, qualidade bioquímica das raízes e atividade da redutase do nitrato nas folhas. Os tratamentos não influenciaram as características de crescimento e rendimento: massa fresca de folhas, massa seca de folhas, área foliar total, comprimento e diâmetro de raiz. A adubação potássica aumentou o conteúdo de vitamina $C$ nas raízes de rabanete e a atividade da redutase do nitrato nas folhas, principalmente quando a fonte de $\mathrm{N}$ utilizada foi o nitrato de cálcio. O maior valor de índice SPAD foi obtido na dose de $51 \mathrm{~kg} \mathrm{ha}^{-1}$ de $\mathrm{K}_{2} \mathrm{O}$. A utilização do sulfato de amônio propiciou maior teor de sólidos solúveis nas raízes.

Palavras-chave: amônio, nitrato, Raphanus sativus L.
\end{abstract}

Nitrogen and potassium are the nutrients most extracted and exported by the radish culture, being essential for the productivity and quality of the roots produced. Thus, the present study was developed with the objective of evaluating changes in plant growth and radish root quality as a function of potassium doses and nitrogen sources. The experiment was conducted in a completely randomized design, with treatments arranged in a 4 x 2 factorial scheme, with four doses of potassium (K), 0, 70, 140 and $210 \mathrm{~kg} \mathrm{ha}^{-1}$ of $\mathrm{K}_{2} \mathrm{O}$ and two sources of nitrogen $(\mathrm{N})$, ammonium sulfate and calcium nitrate, with four replicates. The plants were evaluated for growth, yield, biochemical quality of the roots and nitrate reductase activity in the leaves. The treatments did not influence the growth and yield characteristics: leaf and root fresh mass, leaf dry mass, total leaf area, root length and diameter. Potassium fertilization increased the vitamin $\mathrm{C}$ content in the radish roots and the nitrate reductase activity in the leaves, especially when the $\mathrm{N}$ source used was calcium nitrate. The highest SPAD index value was obtained at a dose of $51 \mathrm{~kg} \mathrm{ha}^{-1}$ of $\mathrm{K}_{2} \mathrm{O}$. The use of ammonium sulfate provided a higher content of soluble solids in the roots.

Keywords: ammonium, nitrate, Raphanus sativus L.

\section{INTRODUÇÃO}

O rabanete (Raphanus sativus L.) é uma olerícola pertencente à família Brassicaceae, apresenta porte pequeno e raiz bulbosa comestível de cor vermelha com sabor picante [1]. Apesar da sua pouca expressão em termos da área plantada, seu cultivo possibilita rápido retorno econômico, devido ao curto ciclo de crescimento, sendo cultivado em um grande número de pequenas propriedades [2].

As raízes do rabanete possuem baixo teor de gordura, são ricas em fibras alimentares [3] e possui propriedades nutracêuticas e medicinais, devido a presença de compostos de cálcio, ferro, 
vitaminas (A, B1, B2 e C) e enxofre, além disso, possui atividades anticarcinogênicas, diuréticas, antiscorbúticas e estimulantes das enzimas digestivas [4].

Nitrogênio e potássio são os nutrientes mais extraídos e exportados pela cultura do rabanete, sendo imprescindíveis para a produtividade e qualidade das raízes produzidas [5, 6]. O nitrogênio (N) é absorvido pelas plantas preferencialmente na forma de nitrato ou amônio [7] e desempenha um papel vital no crescimento e desenvolvimento das plantas, sendo constituinte essencial de proteínas, ácidos nucléicos, clorofila e enzimas [8]. O potássio (K) está envolvido na ativação enzimática, síntese de proteínas, fotossíntese, osmorregulação, extensão celular, produção de cloroplastos, transporte de açúcares e aminoácidos e equilíbrio de cátions e ânions [9].

Os componentes da qualidade normalmente utilizados para caracterizar os rabanetes incluem perda de peso, acidez titulável, potencial hidrogeniônico, sólidos solúveis e conteúdo de vitamina C [10]. Adicionalmente, Kyriacou e Rouphael (2018) [11] destacam que a qualidade pós-colheita e segurança das hortaliças frescas, estão relacionadas ao seu teor residual de nitrato, que favorece a formação de nitrito por meio de enzimas salivares e implica na formação de compostos nitrogenados cancerígenos.

Dentre as hortaliças, o rabanete se caracteriza pela capacidade de acumular altos teores de nitrato em suas raízes [12]. No entanto, plantas de rabanete fertilizadas com $\mathrm{N}$ amoniacal apresentam menor quantidade de nitrato em comparação às supridas com fontes nítricas [13]. Além disso, trabalhos sugerem que o aumento na taxa de aplicação de potássio facilita a absorção e o transporte para a parte aérea da planta, promovendo o metabolismo e a utilização de nitrato $[14,15]$.

Como o amônio e o nitrato impactam de maneira diferente alguns processos morfológicos e bioquímicos das plantas [16] acredita-se que a aplicação combinada de uma destas fontes com o $\mathrm{K}$ possa potencializar o crescimento e a qualidade de raízes de rabanete. Desta forma, o presente trabalho foi desenvolvido com o objetivo de avaliar as alterações no crescimento de plantas e qualidade de raízes de rabanete em função de doses de potássio e fontes de nitrogênio (nítrica e amoniacal).

\section{MATERIAL E MÉTODOS}

O experimento foi conduzido em casa de vegetação na Universidade Estadual do Sudoeste da Bahia, Campus Vitória da Conquista (1453'08'S, 4048'02'O), altitude de $881 \mathrm{~m}$. A classificação do clima é Cwb segundo a Köppen e Geiger, com precipitação média anual de 712 $\mathrm{mm}$ e temperatura média anual de $20^{\circ} \mathrm{C}$. Adotou-se o delineamento inteiramente casualizado, com tratamentos arranjados em esquema fatorial $4 \times 2$, sendo quatro doses de potássio $(\mathrm{K}), 0,70,140$ e $210 \mathrm{~kg} \mathrm{ha}^{-1}$ de $\mathrm{K}_{2} \mathrm{O}(\mathrm{KCl})$ e duas fontes de nitrogênio ( $\left.\mathrm{N}, 200 \mathrm{~kg} \mathrm{ha}^{-1}\right)$, sulfato de amônio $\left(\left(\mathrm{NH}_{4}\right)_{2} \mathrm{SO}_{4}\right)$ e nitrato de cálcio $\left(\mathrm{Ca}\left(\mathrm{NO}_{3}\right)_{2}\right)$, com quatro repetições.

Antes da instalação dos experimentos, foram coletadas amostras de solo, as quais, após homogeneizadas, resultaram em amostra composta, que foi levada ao laboratório para análise química, sendo os resultados (Tabela 1) determinados segundo metodologia descrita por Donagema et al. (2011) [17].

Tabela 1: Caracterização química do solo utilizado no experimento.

\begin{tabular}{|c|c|c|c|c|c|c|c|c|c|c|}
\hline \multirow{2}{*}{$\mathrm{pH}$} & \multirow{2}{*}{$\mathrm{P}\left(\mathrm{mg} \mathrm{dm} \mathrm{m}^{-3}\right)$} & $\mathrm{K}^{+}$ & $\mathrm{Ca}^{2+}$ & $\mathrm{Mg}^{2+}$ & $\mathrm{Al}^{3+}$ & $\mathrm{H}^{+}$ & SB & $\mathrm{t}$ & $\mathrm{T}$ & \multirow{2}{*}{$\begin{array}{l}\mathrm{V} \\
(\%)\end{array}$} \\
\hline & & \multicolumn{8}{|c|}{$\mathrm{cmol}_{\mathrm{c}} \mathrm{dm}^{-3}$ solo } & \\
\hline
\end{tabular}

pH em água; SB: soma de bases; t: capacidade efetiva de troca catiônica; T: capacidade de troca catiônica a pH 7; V: saturação por base.

A semeadura do rabanete (Raphanus sativus L., cv. Crimson gigante) foi realizada em 22 de agosto de 2019, utilizando-se cinco sementes por vaso a uma profundidade de $1 \mathrm{~cm}$. Foram utilizados vasos com capacidade de $3 \mathrm{~L}$, contendo como substrato um solo tipo Latossolo Amarelo [18]. Cinco dias após a emergência (DAE) das plantas, realizou-se o desbaste deixando apenas uma planta por vaso. 
$\mathrm{Na}$ adubação de plantio foram aplicados $\mathrm{K}$ nas doses referente aos diferentes tratamentos, $\mathrm{P}$ (500 $\mathrm{kg} \mathrm{ha}^{-1}$ ou $250 \mathrm{mg} \mathrm{dm}^{-3}$ ) e $20 \%$ do $\mathrm{N}$, aos 7 DAE realizou-se a adubação com os $80 \%$ do $\mathrm{N}$ restante. Aos 14 DAE realizou-se adubação com cobre e boro na dose de 4 e $2 \mathrm{mg} \mathrm{dm}^{-3}[19,30]$, respectivamente. A irrigação foi realizada manualmente, buscando manter a umidade do solo dentro da capacidade de água disponível.

Aos 35 dias após a semeadura (DAS) realizou-se a avaliação do experimento. O índice relativo de clorofila foi determinado em três pontos de folhas totalmente expandidas utilizando-se um clorofilômetro portátil, modelo SPAD-502 (Minolta, Japão).

Por ocasião da colheita, as plantas foram devidamente identificadas, e separadas em parte aérea (folhas) e raiz. A área foliar foi determinada utilizando o medidor de área foliar Area Meter, modelo LICOR LI-3000. As raízes foram lavadas para retirar o excesso de solo e em seguida foram pesadas, assim como a parte aérea, para determinação da massa fresca. Posteriormente, o material colhido (folhas e raízes) foi seco em estufa com circulação forçada de ar a $65 \pm 5^{\circ} \mathrm{C}$, até atingir massa constante, e em seguida quantificou a massa seca. $\mathrm{O}$ diâmetro e comprimento das raízes foram medidos com um paquímetro e expresso em milímetros.

Os rabanetes foram avaliados quanto ao $\mathrm{pH}$, acidez titulável total, sólidos solúveis totais, vitamina $\mathrm{C}$ e atividade da redutase do nitrato. $\mathrm{O}$ pH foi determinado em uma solução obtida pela homogeneização e filtragem de $50 \mathrm{~g}$ da amostra em $100 \mathrm{~mL}$ de água destilada utilizando pHmetro digital devidamente calibrado com solução tampão de pH 4,0 e 7,0 [20].

A acidez titulável total foi determinada por titulação com $\mathrm{NaOH}$, utilizando-se $10 \mathrm{~mL}$ de suco obtido pela homogeneização de $50 \mathrm{~g}$ da amostra triturada com $100 \mathrm{~mL}$ de água destilada, sendo o resultado expresso em \% de ácido cítrico por $100 \mathrm{~g}$ de massa fresca (MF) [21]. O conteúdo de sólidos solúveis totais foi determinado por leitura em refratômetro, a partir do extrato líquido puro das raízes de rabanete, os resultados foram expressos em ${ }^{\circ}$ Brix [21].

A vitamina $\mathrm{C}$ foi determinada utilizando-se o método titulométrico, e os resultados foram expressos em mg de ácido ascórbico por $100 \mathrm{~g}$ de MF [20]. A titulação das amostras foi realizada em triplicata a partir de uma alíquota de $20 \mathrm{~mL}$ da solução contendo $10 \mathrm{~mL}$ do extrato da amostra e $10 \mathrm{~mL}$ da solução de ácido oxálico na proporção de 1:1. Esta alíquota foi titulada com solução de 2,6-diclorofenol indofenol a 0,025\% (DCFI), até o ponto de viragem (coloração rósea) determinado visualmente.

Para determinação da atividade da redutase do nitrato, amostras de $0,5 \mathrm{~g}$ das folhas foram cortadas e adicionadas a tubos de ensaio contendo $5 \mathrm{~mL}$ do meio de incubação, constituído de solução tampão fosfato de potássio $\left(\mathrm{K}_{2} \mathrm{HPO}_{4}+\mathrm{KH}_{2} \mathrm{PO}_{4} 0,1 \mathrm{M}\right.$, pH 7,5), n-propanol $3 \%$ (v/v) e $\mathrm{KNO}_{3} 0,1 \mathrm{M}$ e incubadas em banho-maria, a $30^{\circ} \mathrm{C}$, com agitação, no escuro. Após 30 minutos, alíquotas de $1 \mathrm{~mL}$ foram coletadas dos ensaios enzimáticos e adicionadas a uma solução contendo $1,0 \mathrm{~mL}$ de sulfanilamida $1 \%(\mathrm{p} / \mathrm{v}$ ) em $\mathrm{HCl} 1,5 \mathrm{M}, 1,0 \mathrm{~mL}$ de N-1-naftiletilenodiamina di-HCl $0,02 \%(\mathrm{p} / \mathrm{v})$ e $1,0 \mathrm{~mL}$ de água destilada, para a quantificação de nitrito [22]. As leituras espectrofotométricas foram realizadas a $540 \mathrm{~nm}$, sendo a quantidade de nitrito calculada utilizando-se reta padrão de nitrito de sódio.

Os dados foram inicialmente submetidos ao teste de normalidade e homogeneidade, em seguida procedeu-se à análise de variância e, havendo significância para doses de K, foi realizado a análise de regressão. As médias foram comparadas pelo teste de Tukey com nível de 5\% de significância. As análises estatísticas foram realizadas com auxílio do programa computacional SISVAR [23].

\section{RESULTADOS E DISCUSSÃO}

As características, massa fresca de folhas (MFF), massa seca de folhas (MSF), área foliar total (AFT), diâmetro (DR), comprimento (CR) e massa fresca das raízes (MFR) de rabanete não foram influenciadas pelas doses de potássio e fontes de nitrogênio utilizadas (Tabela 2). Em relação à adubação potássica, resultados similares foram obtidos em outras pesquisas [5, 24], no entanto, alguns estudos têm demonstrado que o potássio influencia positivamente o acúmulo de massa fresca e seca da raiz de rabanete $[6,25,26]$.

Apesar das diferentes fontes de $\mathrm{N}$ não revelarem diferenças significativas para MFF, MSF, AFT, DR, CR e MFR, os valores médios destas características quando se utilizou sulfato de 
amônio foram superiores à utilização de nitrato de cálcio (Tabela 3), o que pode estar relacionado ao fato da assimilação do amônio $\left(\mathrm{NH}_{4}^{+}\right)$requerer um menor custo energético em relação ao nitrato $\left(\mathrm{NO}_{3}^{-}\right)$[27].

Tabela 2: Resumo da análise de variância e coeficiente de variação para massa fresca de folhas (MFF), massa seca de folhas (MSF), área foliar total (AFT), diâmetro de raiz (DR), comprimento de raiz $(C R) e$ massa fresca de raiz (MFR) de plantas de rabanete submetidas a doses de potássio (K) e fontes de nitrogênio $(N)$.

\begin{tabular}{cccccccc}
\hline \multirow{2}{*}{ FV } & \multirow{7}{c}{ GL } & \multicolumn{7}{c}{ Quadrado médio } \\
\cline { 3 - 8 } & & MFF & MSF & AFT & DR & CR & MFR \\
\hline Doses de K & 3 & $8,27^{\text {ns }}$ & $0,13^{\text {ns }}$ & $1451,30^{\text {ns }}$ & $18,37^{\text {ns }}$ & $114,80^{\text {ns }}$ & $181,80^{\text {ns }}$ \\
Fonte de N & 1 & $32,40^{\text {ns }}$ & $0,13^{\text {ns }}$ & $21173,20^{\text {ns }}$ & $0,39^{\text {ns }}$ & $4,13^{\text {ns }}$ & $16,00^{\text {ns }}$ \\
K x N & 3 & $2,02^{\text {ns }}$ & $0,12^{\text {ns }}$ & $93,22^{\text {ns }}$ & $5,47^{\text {ns }}$ & $10,70^{\text {ns }}$ & $125,14^{\text {ns }}$ \\
Erro & 24 & 29,90 & 0,25 & 13948,50 & 22,24 & 149,90 & 130,79 \\
\hline CV $(\%)$ & & 25,65 & 27,6 & 24,7 & 10,4 & 23,1 & 17,16 \\
\hline
\end{tabular}

${ }^{\mathrm{ns}}$ não significativo pelo teste $\mathrm{F}$, a $5 \%$ de probabilidade.

Tabela 3: Valores médios de massa fresca de folhas (MFF), massa seca de folhas (MSF), área foliar total (AFT), diâmetro de raiz (DR), comprimento de raiz (CR) e massa fresca da raíz (MFR) de plantas de rabanete submetidas a doses de $K$ e fontes de $N$.

\begin{tabular}{|c|c|c|c|c|c|c|c|c|c|c|c|c|}
\hline \multirow{2}{*}{$\begin{array}{l}\text { Doses } \\
\text { de K }\end{array}$} & \multicolumn{2}{|c|}{$\begin{array}{c}\text { MFF } \\
\left(\text { g planta }^{-1}\right)\end{array}$} & \multicolumn{2}{|c|}{$\begin{array}{c}\text { MSF } \\
\left(\mathrm{g} \text { planta-1 }^{-1}\right)\end{array}$} & \multicolumn{2}{|c|}{$\begin{array}{c}\text { AFT } \\
\left(\mathrm{cm}^{-2} \text { planta }^{-1}\right)\end{array}$} & \multicolumn{2}{|c|}{ DR (mm) } & \multicolumn{2}{|c|}{$\mathrm{CR}(\mathbf{m m})$} & \multicolumn{2}{|c|}{$\begin{array}{c}\text { MFR } \\
\left(\text { g planta }^{-1}\right)\end{array}$} \\
\hline & SA & $\mathrm{NC}$ & SA & $\mathrm{NC}$ & SA & $\mathrm{NC}$ & SA & $\mathrm{NC}$ & SA & $\mathrm{NC}$ & SA & $\mathrm{NC}$ \\
\hline 0 & 21,25 & 19,50 & 1,80 & 1,70 & 490,6 & 440,2 & 46,03 & 46,30 & 50,50 & 49,00 & 66,70 & 63,50 \\
\hline 70 & 22,40 & 21,67 & 2,07 & 1,87 & 574,6 & 466,1 & 45,00 & 47,50 & 58,00 & 58,07 & 68,90 & 78,50 \\
\hline 140 & 21,96 & 18,95 & 1,77 & 1,60 & 496,7 & 445,2 & 46,06 & 45,50 & 52,05 & 48,60 & 69,00 & 59,70 \\
\hline 210 & 23,58 & 21,02 & 1,85 & 1,82 & 502,1 & 458,5 & 43,75 & 42,38 & 52,25 & 54,25 & 64,76 & 62,10 \\
\hline Média & 22,3 & 20,28 & 1,87 & 1,74 & 516 & 452,5 & 45,21 & 45,42 & 53,2 & 52,48 & 67,34 & 65,94 \\
\hline
\end{tabular}

SA: sulfato de amônio $\left(\left(\mathrm{NH}_{4}\right)_{2} \mathrm{SO}_{4}\right)$ e $\mathrm{NC}$ : nitrato de cálcio $\left(\mathrm{Ca}\left(\mathrm{NO}_{3}\right)_{2}\right)$.

O índice relativo de clorofila foi influenciado pelas doses de $\mathrm{K}$ (Tabela 4), os valores se ajustaram ao modelo cúbico de regressão, onde o maior valor foi obtido na dose calculada de 51 $\mathrm{kg} \mathrm{ha}^{-1}$ de $\mathrm{K}_{2} \mathrm{O}$ e o menor na dose calculada de $178 \mathrm{~kg} \mathrm{ha}^{-1}$ (Figura 1A). Corrêa et al. (2001) [28] também obtiveram valores de índice SPAD ajustados ao modelo cúbico ao avaliarem o efeito de doses de uréia e de nitrato de amônio em Urochloa brizantha. Já Souza et al. (2015) [5] verificaram que o índice relativo de clorofila nas folhas de rabanete aumentou linearmente com aplicação de doses de potássio. A redução do índice SPAD entre as doses de 51 e $178 \mathrm{~kg} \mathrm{ha}^{-1}$ pode está relacionada ao aumento na taxa de crescimento, que altera a redução da concentração de clorofila pelo efeito de diluição [29].

O nível de $\mathrm{pH}$ é indicativo do sabor dos vegetais e geralmente apresenta uma relação inversa com a acidez [1]. O pH das raízes foi influenciado pela interação entre os fatores estudados, pois quando se utilizou sulfato de amônio não houve diferença entre as doses de K (Tabela 4), e quando se utilizou nitrato de cálcio verificou-se menor $\mathrm{pH}$ na dose $210 \mathrm{~kg} \mathrm{ha}^{-1} \mathrm{e}$ na dose de $70 \mathrm{~kg} \mathrm{ha}^{-1}$ (Figura 1B).

Houve diferenças entre as fontes de $\mathrm{N}$ nas doses de 70 e $210 \mathrm{~kg} \mathrm{ha}^{-1}$ de $\mathrm{K}_{2} \mathrm{O}$, na dose 0 as raízes adubadas com sulfato de amônio apresentaram menor $\mathrm{pH}(4,85)$ em relação às adubadas com nitrato de cálcio $(5,30)$. Entretanto, na dose de $210 \mathrm{~kg} \mathrm{ha}^{-1}$ de $\mathrm{K}_{2} \mathrm{O}$ ocorreu o inverso, as raízes adubadas com sulfato de amônio apresentaram maior $\mathrm{pH}(5,19)$ em relação às adubadas com nitrato de cálcio $(4,9)$. Esta alteração no $\mathrm{pH}$ das raízes pode ter ocorrido devido assimilação de $\mathrm{N}$ consumir ácidos orgânicos, ocasionando aumento quando este processo é mais intensificado [30]. Para raízes de rabanete é desejável maior $\mathrm{pH}$, uma vez que menor $\mathrm{pH}$ indica qualidade inferior do produto [31].

Os dados de acidez titulável não foram significativamente influenciados pelas doses de $\mathrm{K}$ e fontes de $\mathrm{N}$ (Tabela 4), apresentando em média 0,54 e 0,62\% de ácido cítrico nas raízes adubadas 
com sulfato de amônio e nitrato de cálcio, respectivamente, sendo superiores ao valor encontrado por Ayub et al. (2013) [1] $(0,34 \%)$.

Tabela 4: Resumo da análise de variância e coeficiente de variação para índice relativo de clorofila (IRC) sólidos solúveis (SS), vitamina $C(V C), p H$, acidez total titulável (ATT) e atividade da redutase do nitrato $(R N)$ de plantas de rabanete submetidas a doses de potássio $(K)$ e fontes de nitrogênio $(N)$.

\begin{tabular}{cccccccc}
\hline \multirow{2}{*}{ FV } & \multirow{2}{*}{ GL } & IRC & SS & VC & pH & ATT & RN \\
\cline { 2 - 8 } & 3 & $35,50^{*}$ & $0,28^{\text {ns }}$ & $178,47^{* *}$ & $0,93^{\text {ns }}$ & $0,17^{\text {ns }}$ & $3,15^{*}$ \\
Doses de K & 3 & $23,12^{\text {ns }}$ & $0,96^{*}$ & $205,33^{* *}$ & $0,13^{*}$ & $0,41^{\text {ss }}$ & $2,14^{*}$ \\
Fonte de N & 1 & $0,66^{\text {ns }}$ & $0,25^{\text {ns }}$ & $96,70^{* *}$ & $0,14^{* *}$ & $0,51^{\text {ns }}$ & $4,75^{* *}$ \\
Interação K x N & 3 & 0,19 & 12,80 & 0,23 & 0,16 & 0,49 \\
Erro & 16 & 12,05 & 0,19 & 6,95 & 3,45 & 21,66 & 24,25 \\
\hline CV $(\%)$ & & 9,04 & 11,29 & &
\end{tabular}

* Significativo pelo teste F, a $\%$ de probabilidade; ${ }^{* *}$ Significativo pelo teste F, a $1 \%$ de probabilidade; ${ }^{\text {ns }}$ não significativo pelo teste $\mathrm{F}$, a $5 \%$ de probabilidade.

Os sólidos solúveis totais (SST) são constituídos por compostos solúveis em água, que representam substâncias, tais como açúcares, ácidos, vitamina $\mathrm{C}$ e algumas pectinas. Por ser constituído principalmente por açúcares, é utilizado como uma medida indireta do teor de açúcares [32]. Como o potássio favorece a formação e translocação de carboidratos [33], estudos tem verificado o efeito positivo do aumento da fertilização potássica no aumento dos SST de frutos $[34,35]$.
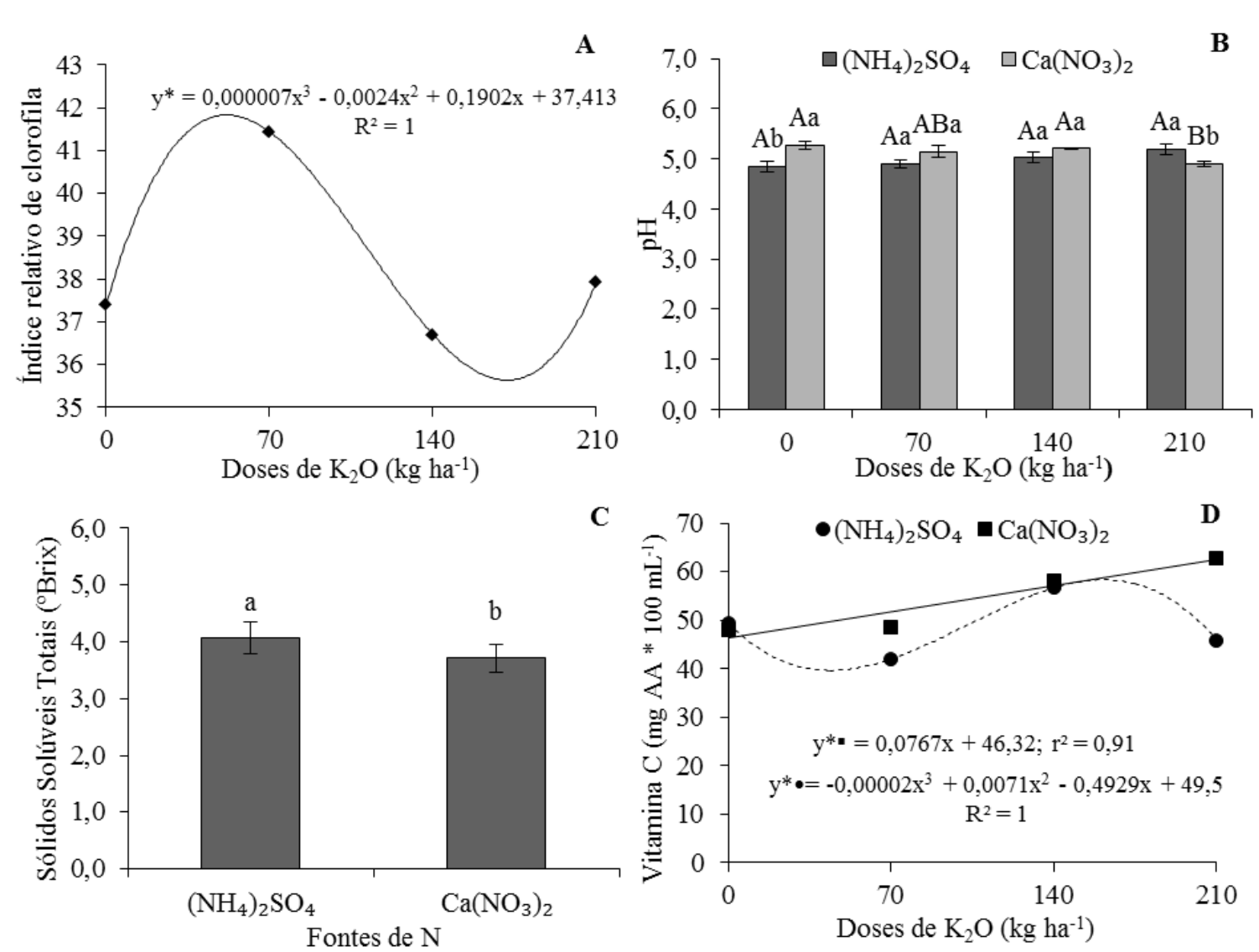

Figura 1: Índice relativo de clorofila em folhas $(A), p H(B)$, sólidos solúveis totais $(C)$ e vitamina $C(D)$ de raízes de rabanete em função de doses de $\mathrm{K}_{2} \mathrm{O}$ e fontes de $\mathrm{N}$.

No entanto, apenas as fontes de N influenciaram o teor de SST nas raízes de rabanete, sendo maior sob adubação com sulfato de amônio (4,06 ${ }^{\circ}$ Brix) (Figura 1C). Valores similares foram verificados por Triphati et al. (2017) [8] para a cv. Kashi Sweta (4,35 ${ }^{\circ}$ Brix), estes autores também 
obtiveram aumento dos SST com o aumento dos níveis de N. Desta forma, o maior conteúdo de SST sob adubação amoniacal pode estar relacionada a uma maior facilidade de assimilação de $\mathrm{N}$ que sob adubação nítrica, uma vez que o $\mathrm{NO}_{3}{ }^{-}$ainda precisa ser reduzido à $\mathrm{NH}_{4}{ }^{+}$para ser assimilado.

Ao utilizar nitrato de cálcio, o aumento das doses de $\mathrm{K}$ promoveu um aumento linear no conteúdo de vitamina $\mathrm{C}$ das raízes de rabanete (Figura 1D). Vários autores têm verificado correlação positiva para o conteúdo de vitamina $\mathrm{C}$ com o aumento dos níveis de $\mathrm{K}[9,34,36]$, o que está relacionado aos efeitos positivos do $\mathrm{K}$ na fotossíntese e síntese de carboidratos, e estes são responsáveis pela manutenção de teores elevados de acido ascórbico [37].

Quando a fonte utilizada foi sulfato de amônio, os dados se ajustaram a um modelo cúbico, o menor conteúdo de vitamina $\mathrm{C}$ foi obtido com $42 \mathrm{~kg} \mathrm{ha}^{-1}$ de $\mathrm{K}_{2} \mathrm{O}$ e o maior com $195 \mathrm{~kg} \mathrm{ha}^{-1}$ de $\mathrm{K}_{2} \mathrm{O}$ (Figura 1D). As variações irregulares no conteúdo de vitamina $\mathrm{C}$ entre as doses de $\mathrm{K}$ sob fonte amoniacal podem ser justificadas pelo fato dos íons $\mathrm{K}^{+}$e $\mathrm{NH}_{4}{ }^{+}$possuírem propriedades físicas semelhantes em termos de carga e diâmetros hidratados [38], desta forma, a presença de $\mathrm{K}^{+}$pode reduzir a captação de $\mathrm{NH}_{4}{ }^{+}$pelas raízes [39].

Quanto se utilizou nitrato de cálcio como fonte de nitrogênio a atividade da enzima redutase do nitrato $(\mathrm{RN})$ foi incrementada pelo fornecimento de $\mathrm{K}$, ajustando-se ao modelo de regressão quadrático (Figura 2A). Verificou-se a máxima atividade da enzima com o fornecimento de $\mathrm{K}_{2} \mathrm{O}$ na dose calculada de $148 \mathrm{~kg} \mathrm{ha}^{-1}$, a partir dessa dose, o aumento no fornecimento de potássio promoveu o decréscimo da sua atividade. A menor atividade da enzima ocorreu na dose zero. $\mathrm{Hu}$ et al. (2017) [40] também verificaram menor atividade desta enzima em folhas de algodão sob deficiência de K, e Gairola et al. (2009) [41] verificaram maior atividade da RN e menor teor de nitrato em folhas de Beta vulgaris submetidas a adubação com potássio.
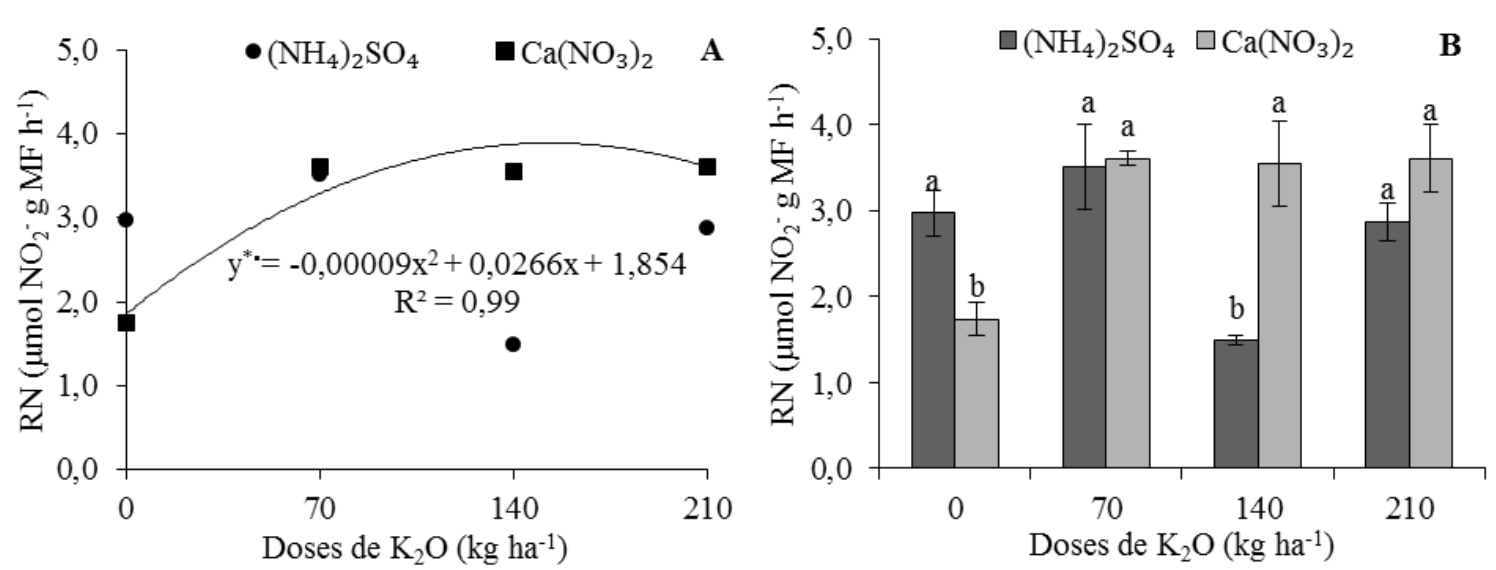

Figura 2: Atividade da enzima redutase do nitrato $(R N)$ em função de doses de potássio $(A)$ e fontes de nitrogênio $(B)$ em folhas de rabanete.

A menor atividade da $\mathrm{RN}$ nas raízes sem o suprimento de $\mathrm{K}$ pode estar relacionada ao fato da deficiência de K limitar a expressão de genes relacionados à absorção de nitrato (NRT2) [42], uma vez que a redução na captação de $\mathrm{NO}_{3}{ }^{-}$ocasiona redução na atividade dessa enzima [43]. De acordo com Wu et al. (2015) [44] com aumento da concentração de nitrato em solução nutritiva, a atividade da $\mathrm{RN}$ exibe tendência crescente nas folhas e nas raízes de rabanete, atingindo um máximo no tratamento com $30 \mathrm{mM}$ nitrato, a partir desta concentração sua atividade é reduzida.

Para que o nitrato seja usado na biossíntese de aminoácidos, proteínas e outros compostos nitrogenados, ele deve ser reduzido a amônio. Nas folhas, a redução de nitrato em nitrito seguida de redução de nitrito em amônio é catalisada respectivamente pelas enzimas, nitrato redutase e nitrito redutase [45]. Como a aplicação de K potencializa a atividade da RN, sua aplicação é desejável para reduzir os riscos à saúde relacionados à toxicidade do nitrato $[11,15]$.

Estes resultados corroboram com os achados de Ahmed et al. (2000) [14] e Ruiz e Romero (2002) [15], que relataram que o aumento na taxa de aplicação de potássio facilita a absorção e o transporte de nitrato para a parte aérea da planta, promovendo o metabolismo e a utilização de nitrato. 
As diferentes fontes de $\mathrm{N}$ afetaram a atividade da $\mathrm{RN}$ nas doses de 0 e $140 \mathrm{~kg} \mathrm{ha}^{-1}$ de $\mathrm{K}_{2} \mathrm{O}$ (Figura 2B). Na dose $0 \mathrm{~kg} \mathrm{ha}^{-1}$ de $\mathrm{K}_{2} \mathrm{O}$, a maior atividade da $\mathrm{RN}$ ocorreu nas plantas adubadas com sulfato de amônio, o que se deve a não utilização de inibidores de nitrificação, desta forma, o $\mathrm{NH}_{4}{ }^{+}$pode ter sido convertido a $\mathrm{NO}_{3}{ }^{-}$pela ação de microrganismos quimioautotróficos [46]. Além disso, os íons de amônio podem promover a atividade da $\mathrm{RN}$ devido à sua contribuição na síntese geral de proteínas [47]. Na dose de $140 \mathrm{~kg} \mathrm{ha}^{-1}$ de $\mathrm{K}_{2} \mathrm{O}$, a atividade da $\mathrm{RN}$ foi inferior nas plantas submetidas a adução com sulfato de amônio, o que comumente ocorre, uma vez que o nitrato é o substrato desta enzima, além disso, o acúmulo de $\mathrm{NH}_{4}{ }^{+}$e outros compostos nitrogenados podem afetar a atividade dessa enzima [48].

Para as demais doses de $\mathrm{K}_{2} \mathrm{O}$ a atividade da $\mathrm{RN}$ foi similar entre as fontes utilizadas, no entanto, estudos demonstram que a atividade desta enzima é reduzida quando se utiliza o $\mathrm{N}$ na forma amoniacal $[45,49]$.

\section{CONCLUSÃo}

A aplicação de potássio e nitrogênio na forma de nitrato de cálcio e sulfato de amônio não influenciaram o crescimento e rendimento de raiz das plantas de rabanete.

A aplicação de potássio aumenta a qualidade das raízes e a atividade da redutase do nitrato em rabanete, principalmente quando associada à adubação nitrogenada com nitrato de cálcio.

\section{AGRADECIMENTOS}

À Universidade Estadual do Sudoeste da Bahia (UESB) pela disponibilidade de infraestrutura para realização da pesquisa, à CAPES, FAPESB e CNPq pelas bolsas concedidas a autores envolvidos na pesquisa.

\section{REFERÊNCIAS BIBLIOGRÁFICAS}

1. Ayub RA, Spinardi B, Gioppo M. Storage and fresh cut radish. Acta Sci Agron. 2013 Apr.June;35(20):241-45, doi.org/10.4025/actasciagron.v35i2.15461.

2. Linhares PCF, Pereira MFS, de Oliveira BS, Henriques GPDSA, Maracaja PB. Produtividade de rabanete em sistema orgânico de produção. Rev Verde Agroecol Desenvolv Sustent. 2010 Dez;5(5):94-101.

3. Chithra S, Anithan T, Suganya M, Lintu T, Lasyaja AB, Gayathri P. Comparison of biochemical analysis and nutritive value of the selected root tubers - Carrot and radish. Int J Adv Sci Res. 2017 March;2(2):41-44.

4. Oliveira GQ, Biscaro GA, Motomiya AVA, Jesus MP, Filho PSV. Aspectos produtivos do rabanete em função da adubação nitrogenada com e sem hidrogel. J Agron Sci. 2014;3:89-100.

5. Souza GP, Lima LGF, Borges IA, Benett CGS, Benett KSS. Manejo da adubação potássica para a cultura do rabanete. Rev Agricul Neotr. 2015 Out-Dez;2(4):60-64.

6. Gouveia AMS, Corrêa CV, De Souza Silva M, De Mendonca VZ, Jorge LG, Martins BNM, Evangelista RM, Cardoso AII. Macro and micronutrients accumulation in radish (Raphanus sativus L.) subjected to potassium (K) fertilization. Aust J Crop Sci. 2018 Nov;12(11):1738-42, doi: 10.21475/ajcs.18.12.11.p1415.

7. Hawkesford W, Horst M, Kichey T, Lambers H, Schjoerring J, Moller IS, White P. Marschner's Mineral Nutrition of Higher Plants. 3a ed, London: Academic Press. Chapter 6, Functions of Macronutrients; p. 135-89, doi: 10.1016/B978-0-12-384905-2.00006-6.

8. Tripathi, AK., Ram RB, Rout S, Kumar A, Patra SS. Studies on the effect of nitrogen levels and spacing on quality traits of radish (Raphanus sativus L.) cv. Kashi Sweta. Int J Chem Stud. 2017 Nov;5(6):53740.

9. Lester GE. Whole plant applied potassium: effects on cantaloupe fruit sugar content and related human wellness compounds. Acta Hortic. 2005 Jun;682(682):487-92, doi: 10.17660/ActaHortic.2005.682.59.

10. Valero DB, Serrano M. Postharvest biology and technology for preserving fruit quality. New York: CRC Press; 2010. p. 49-68.

11. Kyriacou MC, Rouphael Y. Towards a new definition of quality for fresh fruits and vegetables. Sci Hortic. 2018 Apr;234:463-69, doi: 10.1016/j.scienta.2017.09.046.

12. Colla G, Kim HJ, Kyriacou, MC, Rouphael Y. Nitrate in fruits and vegetables. Sci Hortic. 2018 Jul;237:221-238, doi: 10.1016/j.scienta.2018.04.016. 
13. Chohura P, Koota E. The effect of nitrogen fertilization on radish yielding. Acta Sci Polon Hortic. 2011; 10(1):23-30.

14. Ahmed AHH, Khalil MK, Farrag AM. Nitrate accumulation, growth, yield and chemical composition of Rocket (Eruca vesicaria subsp. sativa) plant as affected by NPK fertilization, kinetin and salicylic acid. Ann Agric Sci. 2000 Sep;47(1):495-508.

15. Ruiz JM, Romero L. Relationship between potassium fertilization and nitrate assimilation in leaves and fruits of cucumber (Cucumis sativus) plants. Ann Appl Biol. 2002 Mar;140(3):241-245, doi: 10.1111/j.1744-7348.2002.tb00177.X

16. Guo S, Zhou Y, Shen Q, Zhang F. Effect of ammonium and nitrate nutrition on some physiological processes in higher plants - growth, photosynthesis, photorespiration, and water relations. Plant Biol. 2007;9(1):21-29, doi:10.1055/s-2006-924541

17. Donagema GK, de Campos DB, Calderano SB, Teixeira WG, Viana, JM. Manual de métodos de análise de solo. Rio de Janeiro: Embrapa Solos, 2011. 230 p.

18. IBGE- Instituto Brasileiro de Geografia e Estatística. Mapa de Solos do Brasil. Disponível em: https://mapas.ibge.gov.br/tematicos/solos. Acesso em 05 de junho de 2020.

19. Nunes JAS, Bonfim-Silva EM, Moreira JCF. Produção de rabanete submetido à adubação fosfatada. Rev Centro Univers Patos de Minas. 2014;(5):33-43.

20. AOAC - Association Of Official Analytical Chemists. Official methods of analysis of the AOAC international. $17^{\text {th }}$. Gaythersburh, M.D. 2000.

21. IAL - Instituto Adolfo Lutz. Métodos físico-químicos para análise de alimentos. $4^{\mathrm{a}}$ ed, São Paulo, IV IAL, 2008. $1020 \mathrm{p}$.

22. Guimarães MMC, Cairo PAR, Neves OSC. Crescimento de Eucalyptus urophylla em meio hidropônico com diferentes proporções de nitrato e amônio. Floresta Ambiente. 2014;21(1):52-61, doi: 10.4322/floram.2014.011

23. Ferreira DF. Sisvar: a computer statistical analysis system. Ciênc Agrotec. 2011 Nov-Dec; 35(6):103942, doi: 10.1590/s1413-70542011000600001

24. Cecílio-Filho AB, Dutra AF, Da Silva GS. Phosphate and potassium fertilization for radish grown in a latosol with a high content of these nutrients1. Rev Caat. 2017 Abr-Jun; 30(2):412-19, doi: 10.1590/1983-21252017v30n216rc

25. Maia PME, Aroucha EMM, Silva OMP, Silva RCP, Oliveira FA. Desenvolvimento e qualidade do rabanete sob diferentes fontes de potássio. Rev Verde Agroecologia Desenvolv Sustent. 2011 JanMar;6(1):148-153.

26. Castro BF, Santos LGD, Brito CF, Fonseca VA, Bebé FV. Produção de rabanete em função da adubação potássica e com diferentes fontes de nitrogênio. Rev Ciênc Agrár. 2016 Set;39(3):341-48, doi: 10.19084/RCA15131.

27. Kant S, Kant P, Lips H, Barak S. Partial substitution of $\mathrm{NO}_{3}{ }^{-}$by $\mathrm{NH}_{4}{ }^{+}$fertilization increases ammonium assimilating enzyme activities and reduces the deleterious effects of salinity on the growth of barely. $\mathrm{J}$ Plant Physiol. 2006 Mar;164(3):303-11, doi: 10.1016/j.jplph.2005.12.011.

28. Corrêa LDA, Primavesi O, Primavesi A, Pott E. Teor de clorofila e produção de matéria seca de Brachiaria brizantha cv. Marandu, adubada com duas fontes de nitrogênio. In: Embrapa Pecuária Sudeste-Artigo em anais de congresso (ALICE). In: Reunião Anual Da Sociedade Brasileira De Zootecnia, 38, 2001, Piracicaba (SP):SBZ, 2001. p. 237-238.

29. Backes C, Bôas V, Lyra R, Lima CPD, Godoy LJGD, Büll LT, Santos AJM. Estado nutricional em nitrogênio da grama esmeralda avaliado por meio do teor foliar, clorofilômetro e imagem digital, em área adubada com lodo de esgoto. Bragantia. 2010;69(3):661-68, doi: 10.1590/s000687052010000300018 .

30. Porto JS. Fontes e doses de nitrogênio na produção e qualidade de tomate híbrido silvety [Dissertação]. Vitória da Conquista (BA): Universidade Estadual do Sudoeste da Bahia; 2013. 97 p.

31. Pereira AJ, Blank AF, Souza RJ, Oliveira P M, Lima LA. Efeitos dos níveis de reposição e frequência de irrigação sobre a produção e qualidade do rabanete. Rev. Bras. de Eng. Agrícola e Ambient, 1999;3(1). Disponível em <http://www.agriambi.com.br/revista/v3n1/117.pdf>. Acesso em: 06 jan. 2016

32. Chitarra MIF, Chitarra AB. Pós-colheita de frutas e hortaliças: fisiologia e manuseio. Lavras: UFLA, 2005. $785 \mathrm{p}$.

33. Filgueira FAR. Novo manual de olericultura. 2.ed. Viçosa, MG: UFV, 2003. 418 p.

34. El-Nemr MA.; Abd El-Baky MMH, Salman SR, El-Tohamy WA. Effect of different potassium levels on the growth, yield and quality of tomato grown in sand-ponic culture. Aust J Basic Appl Sci. 2012;6(3):779-84.

35. Lin D, Huang D, Wang S. Effects of potassium levels on fruit quality of muskmelon in soilless medium culture. Sci Hortic. 2001 Oct;102(1):53-60, doi: 10.1016/j.scienta.2003.12.009 
36. Nagy S. Vitamin C contents of citrus fruit and their products: a review. J Agric Food Chem. 1980 Jan; 28(1):8-18, doi: 10.1021/jf60227a026

37. Hosoda H, Nawa Y, Kurogi M. Effect of light quality on postharvest changes of chemical components in komastuna (Brassica campestris L. var. komastuna) leaves. Food Preserv Sci. 2000 Jan; 26(2):1518, doi: $10.5891 /$ jafps.26.81

38. Xu G, Wolf S, Kafkafi U. Ammonium on potassium interaction in sweet pepper. J Plant Nutr. 2002 Aug;25(4):719-34, doi: 10.1081/PLN-120002954

39. Guo J, Jia Y, Chen H, Zhang L, Yang J, Zhang J, Zhang J, Hu X, Ye X, Li Y, Zhou Y. Growth, photosynthesis, and nutrient uptake in wheat are affected by differences in nitrogen levels and forms and potassium supply. Sci. Rep. 2019 Feb; 9(1):1-12, doi: 10.1038/s41598-018-37838-3

40. Hu W, Coomer TD, Loka DA.; Oosterhuis DM, Zhou Z. Potassium deficiency affects the carbonnitrogen balance in cotton leaves. Plant Physiol Bioch. 2017 Apr;115:408-417, doi: 10.1016/j.plaphy.2017.04.005

41. Gairola S, Umar S, Suryapani S. Nitrate accumulation, growth and leaf quality of spinach beet (Beta vulgaris Linn.) as affected by NPK fertilization with special reference to potassium. Indian J Sci Technol. 2009 Mar;2(2):35-40, doi: 10.17485/ijst/2009/v2i2/29390

42. Armengaud P, Breitling R, Amtmann A. The potassium-dependent transcriptome of Arabidopsis reveals a prominent role of jasmonic acid in nutrient signaling. Plant Physiol. 2004 Sep;136:2556-76, doi: $10.1104 / \mathrm{pp} .104 .046482$

43. Somers DA, Kuo TM, Kleinhofs A, Warner RL, Oaks A. Synthesis and degradation of barley nitrate reductase. Plant Physiol. 1983 Aug; 72:948-52, doi: 10.1104/pp.72.4.949

44. Wu Y, Zhang W, Xu L, Wang Y, Zhu X, Li C, Liu L. Isolation and molecular characterization of nitrite reductase (RsNiR) gene under nitrate treatments in radish. Sci Hortic. 2015 Sep;193:276-85, doi: 10.1016/j.scienta.2015.07.016

45. Balotf S, Kavoosi G, Kholdebarin B. Nitrate reductase, nitrite reductase, glutamine synthetase, and glutamate synthase expression and activity in response to different nitrogen sources in nitrogen-starved wheat seedlings. Biotechnol Appl Bioc. 2016 May; 63(2):220-229, doi: 10.1002/bab.1362

46. Vieira RF. Ciclo do nitrogênio em sistemas agrícolas. Brasília: Embrapa; 2017. 163 p.

47. Mehta P, Srivastava HS. Comparative stability of ammonium-and nitrate-induced nitrate reductase activity in maize leaves. Phytochemistry. 1980;19(12):2527-30, doi: 10.1016/S0031-9422(00)83912-6

48. Lewis OAM, James DM, Hewitt EJ. Nitrogen assimilation in barley (Hordeum vulgare L. cv. Mazurca) in response to nitrate and ammonium nutrition. Ann Bot. 1982 Jan; 49(1):39-49, doi: 10.1093/oxfordjournals.aob.a086228

49. Sood CR, Chanda SV, Singh YD. Nitrate reductase activity as affected by phytohormones and different nitrogen sources. Acta Physiol Plant. 2012 Apr;22(4):477-82, doi: 10.1007/s11738-000-0092-4 